\title{
Abortamento legal após estupro: histórias reais, diálogos necessários
}

\author{
Legal abortion after rape: true stories, necessary dialogues
}

Maria Cristina Dias de Lima', Liliana Muller Larocca', Dênis José Nascimento'

DOI: 10.1590/0103-1104201912110

RESUMO Estudo de caso documental e descritivo com abordagem qualitativa. Teve por objetivo reconhecer os discursos expressos nos Termos de Relato Circunstanciado (TRC), registrados no período de janeiro de 2009 a dezembro de 2015, de mulheres acima de 18 anos que solicitaram o abortamento no Complexo Hospital de Clínicas da Universidade Federal do Paraná. Nos TRC são relatadas as violências sofridas bem como a afirmação do desejo por interrupção da gestação. A análise dos dados foi realizada com apoio do software WebQDA. Foram identificados 58 relatos, os quais depois de analisados, possibilitaram a identificação das 20 palavras mais frequentes nos discursos, dando visibilidade às histórias de violências vividas pelas participantes. Concluiu-se que a pesquisa trouxe uma importante reflexão quanto à violência sexual em mulheres, bem como sua relação com questões de gênero. Foi possível identificar a partir dos discursos que as relações de poder estabelecidas acerca do fenômeno interferem diretamente nos comportamentos e condutas pós-violência sexual, culminando em gestações indesejadas. A necessidade de ampliar discussões que reflitam sobre conceitos enraizados historicamente é imprescindível, avançando, assim, no combate às relações de violência contra mulheres.

PALAVRAS-CHAVE Delitos sexuais. Violência contra a mulher. Aborto legal. Software.

ABSTRACT This is a documentary and descriptive case study with a qualitative approach. The goal of this study was to identify the statements expressed in the Terms of Detailed Accounts (TDA), registered between January 2009 and December 2015, of women over 18 who requested abortion at the Hospital Complex of the Federal University of Paraná. The violence suffered and the assertion of a desire to interrupt the pregnancy are reported in the TDAs. Data analysis was performed with the support of the WebQDA software. Fifty-eight reports were identified, which were then analyzed, allowing the identification of the 20 most frequent words in the statements, giving visibility to the stories of violence experienced by the participants. It was concluded that the research brought an important reflection on sexual violence toward women, as well as its association to gender issues. It was possible to identify from the statements that the established power relations around the phenomenon interfere directly on the behaviors and actions after sexual violence, culminating in unwanted pregnancies. The need to expand discussions that contemplate historically rooted concepts is essential, thus promoting the fight against violence towards women.

1 Universidade Federal do Paraná (UFPR) - Curitiba (PR), Brasil.

mariacrissllima@gmail.com
KEYWORDS Sex offenses. Violence against women. Abortion, legal. Software. 


\section{Introdução}

A temática da violência sexual vem sendo amplamente discutida em todo o mundo apesar de não ser uma problemática exclusiva da atualidade. Estudo realizado em 56 países estima que 1 em cada 14 mulheres no mundo já sofreu violência sexual praticada por homens desconhecidos $\mathbf{1}$. De acordo com o Anuário Brasileiro de Segurança Pública, com dados de registros policiais realizados no ano de 2014, “[...] uma pessoa foi estuprada a cada 11 minutos"2(116).

No Brasil, o crime de estupro está previsto no Código Penal Brasileiro e é definido como:

Art. 213 Constranger alguém, mediante violência ou grave ameaça, a ter conjunção carnal ou a praticar ou permitir que com ele se pratique outro ato libidinoso ${ }^{3(54)}$.

No ano de 1998, ocorreram no Brasil diversas discussões sobre as consequências da violência sexual às vítimas, em sua grande maioria do sexo feminino. Em 1999, o Ministério da Saúde instituiu a primeira norma técnica para atendimento integral de violência sexual, intitulada: Prevenção e Tratamento dos Agravos Resultantes da Violência Sexual Contra Mulheres e Adolescentes ${ }^{4}$. Desde então, as demais normas técnicas editadas foram revistas e ampliadas.

No município de Curitiba, o atendimento à violência sexual acontece com base no Programa Mulher de Verdade - Atenção à Mulher em Situação de Violência ${ }^{5}$, instituído em 2002 pela Secretaria Municipal de Saúde e norteado pelo protocolo do Ministério da Saúde. É parte integrante do protocolo a realização do abortamento legal a mulheres que engravidaram em decorrência do crime de estupro. Tal direito está previsto no Código Penal Brasileiro em seu art. $\mathrm{n}^{0} 128$, inciso II e compõe a Norma Técnica de Atenção Humanizada ao Abortamento do Ministério da Saúde ${ }^{6,7}$.

A problemática deste estudo vem justamente na contramão de alguns aspectos do protocolo de atendimento, visto que as suas participantes, por alguma razão, não chegaram até os serviços de saúde que realizam profilaxias para possíveis contaminações por doenças infecciosas e contracepção de emergência no período de até 72 horas após a violência sofrida. Dentro desse universo, buscou-se reconhecer os discursos expressos nos Termos de Relato Circunstanciado (TRC), documento solicitado para a realização do abortamento, dando visibilidade aos aspectos que permeiam a questão da violência sexual, desmistificando conceitos preestabelecidos que, por vezes, naturalizam o fenômeno e culpabilizam as mulheres. Segundo $\mathrm{Kosik}^{8}$, fenômenos possuem essências ocultas, destarte, o objetivo do estudo foi conhecer a realidade objetiva dos casos de violência sexual contra mulheres que solicitaram o abortamento legal na instituição investigada.

É importante lembrar que, apesar de ser um direito, a decisão das mulheres que buscam pelo abortamento é árdua e complexa. Descobrir-se grávida de um agressor é, sem dúvida, uma nova situação de violência. Além disso, a questão do abortamento é carregada de preconceitos e julgamentos morais por parte da sociedade e não raro pelas próprias mulheres violentadas que expressam se sentirem culpadas por não desejar levar adiante a gestação. Enfrentar seus próprios preceitos morais, expondo para profissionais da rede de atendimento o ocorrido, além dos sintomas gestacionais e, muitas vezes, da falta de suporte familiar, faz deste enfrentamento um longo e doloroso percurso.

Descrito no Código Penal Brasileiro desde 1940, art. 128, é considerada lícita a interrupção da gestação decorrente de violência sexual ${ }^{6}$. No direito, é também denominado como aborto sentimental, lícito, ético ou humanitário.

O consentimento por escrito das mulheres é fundamental para a realização do abortamento. Pautada em tratados e convenções internacionais acerca dos direitos sexuais e reprodutivos, a assistência às mulheres em situação de abortamento legal está prevista no âmbito dos direitos humanos, devendo, portanto, ser observada e garantida. 
Na perspectiva do atendimento integral, o Ministério da Saúde, no ano de 1999, organizou não só o atendimento para casos de violência sexual em até 72 horas como também a norma técnica específica para nortear todo o procedimento de abortamento legal, intitulada: Norma Técnica de Prevenção e Tratamento dos Agravos Resultantes da Violência Sexual Contra Mulheres e Adolescentes ${ }^{\mathbf{1 0}}$. Neste documento, estão descritos de forma clara e acessível aos profissionais de saúde o passo a passo para a realização do atendimento e os aspectos legais que o permeiam.

O fluxo estabelecido para essas situações ocorre de forma a viabilizar a prioridade que o caso requer, desde o acolhimento até sua finalização, independentemente de qual seja. Quando a mulher procura pela interrupção da gestação, traz consigo dúvidas e angústias, revive o momento da violência, mesmo sem ainda o ter superado. Dessa forma, é fundamental que a abordagem profissional viabilize o acesso à saúde, sem discriminação, norteada por princípios como igualdade, liberdade e dignidade da pessoa humana"1.

Para além do abortamento legal, é oferecida à mulher a possibilidade de levar adiante a gestação, com acompanhamento de equipe multiprofissional no pré-natal da própria instituição, optando por ficar com a criança ou deixá-la para adoção, garantindo a legalidade do processo de adoção, desde que realizado com acompanhamento da instituição de saúde ${ }^{10}$.

A documentação prevista oficialmente consiste no exame de ultrassonografia e TRC, documento no qual a mulher descreve a história da violência sofrida e o desejo por interromper a gestação, datado, assinado e posteriormente anexado em seu prontuário.

\section{Métodos}

Trata-se de um estudo de caso documental descritivo, o qual viabilizou a investigação de um fenômeno contemporâneo, dentro de seu contexto, preservando o caráter unitário ${ }^{\mathbf{1 2}}$.
Quanto aos meios, utilizou-se da pesquisa documental devido ao acesso a documentos institucionais para coleta de dados. Quanto aos fins, o estudo descritivo possibilitou a exposição de características do fenômeno investigado ${ }^{13}$. $\mathrm{O}$ recorte temporal da pesquisa compreendeu o período de 2009 a 2015. O ano de 2009 se deve pela implantação do Sistema de Vigilância de Violências e Acidentes (Viva) integrado ao Sinan Net, que possibilitou a sistematização das informações tabuladas das Fichas de Notificação de Violência; e o ano final, devido às investigações consideradas encerradas.

A coleta de dados foi realizada nos prontuários das participantes, nos quais se encontram os TRC, que consistem na descrição detalhada das circunstâncias da violência sofrida, como: local, horário, número de agressor(es) e características deste(s). $\mathrm{O}$ anonimato das mulheres foi preservado, identificando-se cada caso por meio da abreviação RC, seguida de sequência numérica, como RC1, RC2 e assim sucessivamente.

A análise dos dados foi realizada por meio do WebQDA, software de apoio à análise qualitativa acessado por meio da internet em um ambiente seguro de trabalho colaborativo ${ }^{\mathbf{1 4}}, \mathrm{o}$ que permitiu analisar os TRC identificando por meio de nuvem de palavras que apareceram com maior frequência nos relatos das mulheres que solicitaram o abortamento legal. Com a alternativa de excluir palavras que não possuíam relevância discursiva para análise, como pronomes, preposições etc., após leitura exaustiva dos relatos, foram selecionadas apenas palavras que permitiram a análise textual.

O WebQDA é composto de três partes dinâmicas e flexíveis para se adaptar aos diversos modelos e processos de análise qualitativa de dados. Por meio dessa interação, fornece elementos que irão apoiar o investigador na escrita de resultados, no processo de validação e de articulação com outros investigadores. Esse sistema pode ser utilizado de forma colaborativa entre os participantes desde o primeiro momento do processo de investigação e ser alimentado em estágios cíclicos ou por 
completo na fase final da investigação. Suas três partes - fontes, codificações e questionamento - foram utilizadas da seguinte forma: as fontes foram digitadas em formato Word ${ }^{\circledR}$ por meio dos conteúdos dos TRC encontrados nos prontuários e armazenados em arquivo denominados 'Pastas' na ferramenta utilizada; nas codificações, foram utilizadas como critério de exclusão as palavras que fazem parte de uma conjuntura geral (pronomes etc.), que poderiam ser retiradas sem alterar o contexto, de forma a identificar melhor as mais significativas para a discussão em torno da temática; no que tange ao questionamento, utilizou-se do software a ferramenta 'Palavras Mais Frequentes' com o intuito de identificar as palavras que mais apareciam nos relatos utilizados como fonte. Nessa etapa, foi possível optar como critério de exclusão da ferramenta a Dimensão Mínima de caracteres de cada palavra e a Quantidade Máxima de palavras a ser considerada no questionamento.

O cenário do estudo (unidade caso) foi o Complexo Hospital de Clínicas (HC), órgão suplementar da Universidade Federal do Paraná (UFPR), hospital terciário de atendimento 100\% Sistema Único de Saúde (SUS), localizado no município de Curitiba (PR). Na subdivisão por regionais, dentro do mapa político do estado do Paraná, caracteriza-se como referência para a macrorregional Leste, a qual engloba sete regionais de saúde, contemplando 93 municípios ${ }^{15}$. O critério de inclusão foram os prontuários relacionados das mulheres que entregaram o TRC, independentemente de terem ou não realizado o procedimento.

O projeto de pesquisa foi submetido ao Comitê de Ética em Pesquisa em Seres Humanos do HC-UFPR de acordo com a Resolução no 466/2012 e Norma Operacional $n^{\circ}$ 001/2013 do Conselho Nacional de Saúde. Foi resguardado o sigilo da pesquisa, sem nominação das mulheres cujos respectivos prontuários e banco de dados do Sistema de Informação de Agravos de Notificação (Sinan) foram consultados, sendo, nesse caso, solicitada a dispensa da utilização do Termo de
Consentimento Livre e Esclarecido (TCLE) para o Comitê de Ética. A aprovação consta no Parecer de número 1.474.539.

\section{Resultados e discussão}

Embora o presente artigo tenha por objetivo a análise dos TRC na perspectiva da pesquisa qualitativa, cabe salientar que houve uma etapa quantitativa anterior, que subsidiou a discussão proposta neste estudo ${ }^{16}$. Por meio do banco de dados do Sinan, foram identificados 100 casos de violência sexual relacionados com gestação em mulheres, sendo que, destas, a princípio, 75 solicitaram abortamento legal de 2009 a 2015, as demais já estavam gestantes no momento da violência, informação verificada somente quando da pesquisa realizada nos prontuários.

Da amostra de 100 mulheres, foram obtidos os seguintes resultados: 91\% delas possuíam menos de 35 anos, $75 \%$ eram brancas, $52 \%$, solteiras. Em $42 \%$ dos casos a violência ocorreu no período das $19 \mathrm{~h}$ às $23 \mathrm{~h} ; 51 \%$ das violências, em via pública; e em $75 \%$ dos casos, o agressor era desconhecido. Das 75 mulheres que solicitaram de fato o abortamento, 58 mulheres entregaram efetivamente os TRC, as demais não deram sequência no processo de solicitação.

Embora os resultados quantitativos não sejam específicos da amostra das 58 mulheres que entregaram os relatos, dizem muito sobre a violência fortuita vivenciada por todas elas.

Como resultado da etapa qualitativa, trabalhou-se com os 58 relatos no WebQDA, independentemente de ter sido ou não realizado o procedimento de abortamento.

Conforme descrito anteriormente, o software WebQDA permitiu um filtro de palavras mais frequentes com no mínimo quatro caracteres em um total de 20 palavras. A partir desse filtro, foi composto um quadro de palavras, demonstrando a quantidade em que estas se repetem nos TRC e o seu número de caracteres, conforme apresentado no quadro 1 a seguir: 


\begin{tabular}{|c|c|c|}
\hline Palavra & Repetição & Caracteres \\
\hline Carro & 51 & 5 \\
\hline Gravidez & 43 & 8 \\
\hline Medo & 41 & 4 \\
\hline Aborto & 37 & 6 \\
\hline Vida & 31 & 4 \\
\hline Hospital & 30 & 8 \\
\hline Deus & 29 & 4 \\
\hline Homem & 29 & 5 \\
\hline Criança & 21 & 7 \\
\hline Ninguém & 21 & 7 \\
\hline Desespero & 17 & 9 \\
\hline Menstruação & 17 & 11 \\
\hline Violência & 17 & 9 \\
\hline Exames & 16 & 6 \\
\hline Vergonha & 16 & 8 \\
\hline Estupro & 15 & 7 \\
\hline Noite & 15 & 5 \\
\hline Polícia & 15 & 7 \\
\hline Alguém & 13 & 6 \\
\hline Boletim & 13 & 7 \\
\hline
\end{tabular}

Fonte: WebQDA (2017)15.

Para além das palavras retiradas na etapa das codificações, uma vez elaborada a lista das palavras mais frequentes, foram identificadas palavras que apareciam de forma distinta, mas que possuíam o mesmo significado, o que permitiu fazer exclusões considerando aquelas que possuíam maior número de citações na lista, excluindo-se as demais, como foi o caso das palavras 'boletim de ocorrência', que possui significado único, porém contabilizada separadamente pelo software. Demais sinônimos, como criança e bebê, por exemplo, seguiram a mesma lógica.

A partir do referido quadro, o WebQDA viabilizou uma nuvem de palavras, a qual propiciou visualmente a percepção das mais frequentes e que aparecem em maior destaque (sobressaindo-se por cor e tamanho), sendo gradativamente menos destacadas as que foram encontradas em menor número, conforme observado na figura 1. 
Figura 1. Nuvem de palavras gerada pelo WebQDA.

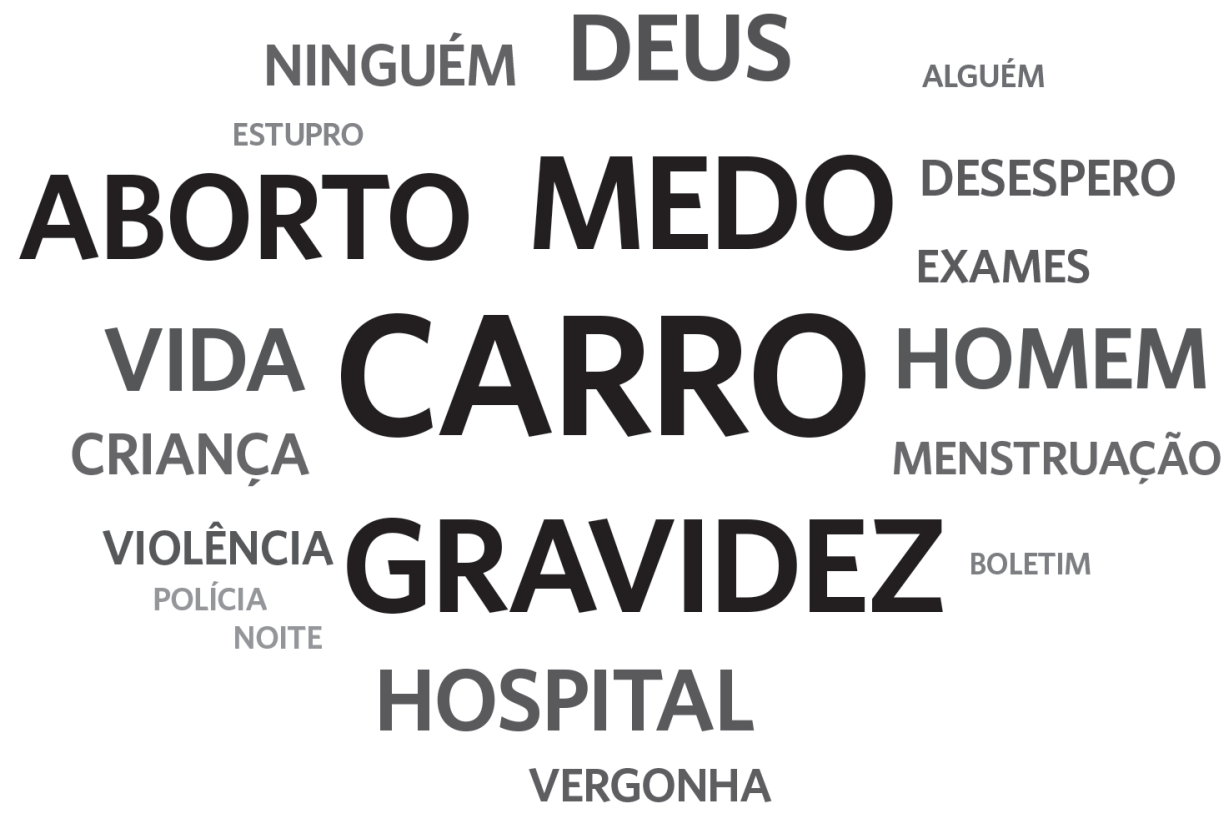

Fonte: WebQDA ${ }^{15}$

Após a identificação das palavras, foram escolhidas algumas frases nos TRC que possibilitassem a referência a estas, salientando-se que tais escolhas foram uma opção de amostragem intencional, tendo em vista selecionar as frases que reproduziam de forma mais significativa a palavra selecionada.

A palavra 'carro' foi a que mais se repetiu em todos os TRC, apresentando-se mais de uma vez em alguns casos, o que permitiu inferir que ela possui relação direta com a violência sexual, identificando-se 19 casos especificamente. Tal palavra pode significar, na prática, que veículos podem ser um facilitador para a ocorrência da violência, em diferentes contextos: agressores de posse de veículos utilizam-nos para cometer o estupro, seja por meio de caronas ofertadas, seja utilizando o automóvel para abordagem de mulheres em via pública; ou até mesmo mulheres de posse de veículos sendo interceptadas por agressores. Fica claro, nesse contexto específico, que agressores podem praticar a violência nas mais variadas circunstâncias. Diversas situações relatadas estão ligadas ao vocábulo, as quais estão identificadas no quadro 2 a seguir: 
Quadro 2. Relatos de violência sexual nos quais a palavra carro foi a mais recorrente - WebQDA

Mulheres abordadas em via pública por [...] eu estava distraída, com um fone de ouvido e percebi que havia parado um carro agressor em carro logo atrás de mim [...] o indivíduo me abordou pegando no meu braço esquerdo já pedindo para mim não olhar para ele e nem gritar e colocou uma faca abaixo de minha costela e me levou de frente para o matagal. (RC 18).

Mulheres que estavam em seus próprios carros

Mulheres que aceitaram carona de conhecidos

Término de namoro no carro do namorado
[...] dois homens me ofereceram ajuda devido o meu carro ter parado de funcionar, não deu tempo de mais nada, cometeram os dois o ato na vagina e no ânus, eram pessoas desconhecidas [...]. (RC 56).

[...] um dos colegas ofereceu carona, disse que já ia levar outras pessoas em seu carro, aproveitava e me levava, ele já havia levado outras vezes e sabia onde eu morava, não senti uma ameaça ali [...]. (RC 49).

[...] no carro, disse a ele que não queria mais ficar com ele, foi quando entrou em uma rua e perguntou, como assim, você tá louca? [...] tentei sair do carro mas não pude, e nem consegui, não tive forças ele segurou meu cabelo com força e subiu em cima de mim tirando minha roupa e me violentando ali mesmo [...]. (RC14).

Fonte: Lima16.

\section{As demais palavras mais encontradas nos TCR estão demonstradas, na sequência, por meio do quadro 3:}

\begin{tabular}{|c|c|}
\hline Gravidez & $\begin{array}{l}\text { [...] e agora não consigo levar adiante esta gravidez pois não consigo aceitar e nem olhar como uma gravidez } \\
\text { [...]. (RC 21). }\end{array}$ \\
\hline Medo & [...] depois do acontecido fiquei com muito medo e sem saber que atitude tomar [...]. (RC 25). \\
\hline Aborto & [...] firmo, uma vez mais o meu desejo urgente, de seguir com o aborto legal [...]. (RC 54). \\
\hline Vida & $\begin{array}{l}\text { [...] estou fazendo este relato no intuito de interromper esse desastre na minha vida, visto que é vindo de uma } \\
\text { situação totalmente indesejada e estúpida, violenta [...]. (RC 7). }\end{array}$ \\
\hline Hospital & [...] tomei a pílula, mas não adiantou, se eu soubesse teria ido no hospital [...]. (RC 3). \\
\hline Deus & [...] fiquei totalmente descontrolada comecei a gritar e pedir pelo amor de Deus para ele parar [...]. (RC 4). \\
\hline Homem & [...] me deparei com um homem vindo no sentido contrário do meu [...]. (RC 37). \\
\hline Criança & [...] quero tirar essa criança eu não aguento mais esse pesadelo que está em mim [...]. (RC 52). \\
\hline Ninguém & [...] não relatei o fato a ninguém, acreditei que superaria com o tempo [...]. (RC 41). \\
\hline Desespero & $\begin{array}{l}\text { [...] entrei em desespero, só queria colocar uma pedra sobre esse fato e fingir que nada aconteceu, mas a gesta- } \\
\text { ção era um fardo demais para carregar [...]. (RC 12). }\end{array}$ \\
\hline Menstruação & [...] quando minha menstruação atrasou fiz três exames de farmácia e todos deram positivo [...]. (RC 36). \\
\hline Violência & [...] filhos são fruto de amor e não de violência [...]. (RC 55). \\
\hline Exames & [...] comecei a fazer exames porque não parava de passar mal e a sentir dores para ir ao banheiro [...]. (RC 19). \\
\hline Vergonha & [...] sentia vergonha e medo, de contar e tudo tomar uma dimensão maior [...]. (RC 43). \\
\hline Estupro & [...] meu desejo de interromper minha gestação, sendo esta, fruto de estupro [...]. (RC 54). \\
\hline Noite & [...] na noite, voltando da igreja, fui abordada por um homem desconhecido [...]. (RC 51). \\
\hline Polícia & [...] falava no meu ouvido, chama a polícia agora, quero ver você ter coragem de chamar [...]. (RC 48). \\
\hline Alguém & $\begin{array}{l}\text { [...] se você me denunciar ou contar para alguém o que eu fiz com você, eu volto aqui e mato você e seus filhos } \\
{[\ldots . .] \text {. (RC 27). }}\end{array}$ \\
\hline Boletim & $\begin{array}{l}{[. . .] \text { resolvi pedir ajuda no centro de atendimento a mulheres vítimas de violência doméstica }[\ldots . .] \text { fui orientada a }} \\
\text { fazer o boletim de ocorrência e em seguida fui encaminhada ao HC [...]. (RC 10). }\end{array}$ \\
\hline
\end{tabular}

Fonte: Lima16. 
As palavras mais citadas nos relatos permitiram relacionar as características similares que possuem as situações de violência sexual, apesar das diversificadas histórias apresentadas. São mulheres que não se conhecem, em contextos diversos, violentadas por variados agressores. Além da violência possuir, portanto, uma caracterização, na verdade, o que se encontra por detrás de todos esses contextos são as relações de poder de homens - nesse caso, agressores - para com as mulheres. Tratase de situações distintas, porém com similaridades que, na verdade, relacionam-se com o papel da mulher na vida pública, uma vez que a violência perpetrada se deu, conforme dados do Sinan, em sua grande maioria, de forma fortuita, em via pública.

Sentimentos como 'medo', 'desespero', 'vergonha' foram frequentemente relatados e aparecem nos discursos expressos. Referências desesperadas com relação à 'vida', a 'Deus', podem demonstrar a grande angústia dessas mulheres ante a gravidez decorrente de um estupro. As expressões 'ninguém' e 'alguém' também possuem relação com tais sentimentos, uma vez que a alusão a 'ninguém' significou a opção das mulheres em não dividir suas histórias, enquanto a menção a 'alguém' possui relação direta com ameaças dos agressores para que não contassem sobre o ocorrido. Tais palavras, portanto, subsidiaram não só a decisão em manter o sigilo sobre a violência sofrida, mas também o poder do agressor sobre essas mulheres ainda que posterior à violência.

Uma vez não procurado, por diversas razões, o atendimento de saúde logo após a violência sexual, as mulheres acreditam que irão superar o ocorrido, que irão esquecer o trauma sofrido ${ }^{18}$. Todavia, diante uma gestação indesejada, o que se pretendia deixar para trás ressurge enquanto consequência ainda da violência. $\mathrm{O}$ desejo de interromper a gestação passa a ser iminente.

Estudo realizado no Hospital da Mulher em Campinas (Universidade Estadual de Campinas - Unicamp), com 10 mulheres de 18 a 38 anos, que buscaram pelo acesso de interromper legalmente suas gestações decorrentes de estupro, aponta que estas relataram que a violência sexual que sofreram foi tão impactante que acabou afetando suas condições de buscar ajuda. Afirmaram ainda que não revelando o acontecido, fariam que o evento fosse esquecido ${ }^{18}$. Nesse mesmo estudo, tais mulheres desconheciam os serviços de atendimento para violência sexual, bem como a importância com a saúde após o ocorrido. A procura por atendimento de saúde ocorreu a partir do atraso menstrual, associado a sintomas físicos, afirmando que somente nesse momento descobriram o direito legal de interromper a gestação.

Já no estudo de caso em que resultou o presente artigo, 17 mulheres, por meio de seus relatos, fizeram referência ao direito previsto em lei de interromper a gestação, colocando-se como protagonistas nesse difícil processo, número restrito considerando um direito previsto desde 1940 no Código Penal Brasileiro, demonstrando, no mínimo, o desconhecimento acerca da legislação que possui relação direta com a realidade das mulheres.

Segundo Machado ${ }^{19}$, em pesquisa realizada com homens encarcerados pelo crime de estupro, não é somente uma questão sexual, mas envolve o fato de sentir-se poderoso, de humilhar a mulher, da posse sobre outra pessoa. Ainda nessa mesma pesquisa, alguns agressores não compreendem como crime se a mulher estava sozinha à noite, colocando-a como disponível e acessível ao desejo daquele homem. A autora referenda a dificuldade das mulheres em levar adiante denúncias de estupro, devido a uma possível atribuição de culpa, bem como pela vergonha que recai sobre elas. A cultura machista, patriarcal, apresenta-se de forma naturalizada e transversal na história e no mundo, objetivando naturalizar a subserviência das mulheres.

Apesar de não ser obrigatória a realização do Boletim de Ocorrência (B.O.), o protocolo de atendimento sugere que, na abordagem com as mulheres quando da solicitação do abortamento, seja orientada a realização de 
uma denúncia formal. Todavia, é apenas uma sugestão, não devendo ser considerada enquanto exigência para a realização do procedimento. Tal instrumento é o primeiro passo para a criminalização do agressor, mas não é o único, sendo necessária a representação no momento da realização do B.O. ou no prazo de seis meses.

Segundo Prata ${ }^{20}$, defensora pública do estado de São Paulo, o desestímulo por profissionais em algumas delegacias para que a representação de fato aconteça associado a outros fatores podem estar ligados ao baixo número de casos levados à instância judicial. A autora expressa que a falta de acolhimento dos profissionais que prestam o atendimento, com questionamentos quanto ao comportamento das mulheres agredidas, reforça a cultura da culpabilização das mulheres.

Pesquisa realizada pelo Instituto de Pesquisa Econômica Aplicada ${ }^{21}$ (Ipea), em municípios metropolitanos e não metropolitanos das cinco grandes regiões do País, com uma amostra de 3.810 indivíduos de ambos os sexos, apresentou dados alarmantes no que diz respeito à violência sexual contra mulheres. Diante da afirmação 'Mulheres que usam roupas que mostram o corpo merecem ser atacadas', $58,4 \%$ discordaram totalmente, contra $13,2 \%$ que concordaram totalmente. Ademais, nos outros percentuais de opiniões: $11,6 \%$ discordam parcialmente, $12,8 \%$ concordaram parcialmente e $3,4 \%$ contabilizados como neutros. Somados os que não discordaram totalmente, tem-se um universo de $41 \%$ de opiniões que, totalmente ou parcialmente, acreditam que as mulheres merecem ser atacadas devido às roupas que estão vestindo, incluindo aqueles caracterizados como nulos. Na mesma pesquisa, a colocação de outra afirmação, 'Se as mulheres soubessem se comportar, haveria menos estupros', apresentou os seguintes percentuais: $30,3 \%$ discordaram totalmente, contra $35,3 \%$ que concordaram totalmente; 7,6\% discordaram parcialmente; $23,2 \%$ concordaram parcialmente e $2,6 \%$ neutros. Da mesma forma, se somados os percentuais daqueles que não discordaram totalmente, tem-se um total de $68,7 \%$ de pessoas que concordam em parte ou totalmente com a referida afirmativa ${ }^{\mathbf{2 1}}$.

Dessa forma, pode-se certificar que as mulheres são responsabilizadas perante a sociedade, devido a comportamentos inadequados, pelo estupro que sofreram²

De acordo com Cerqueira, diretor do Ipea, a discussão sobre a violência sexual é necessária, para que as vítimas não se sintam culpadas, viabilizando a procura pelas autoridades. Tal afirmação surgiu diante da carência de dados para formulação de políticas públicas referentes à violência sexual22.

Não somente na sociedade brasileira mulheres são as mais afetadas pela violência sexual. Inquérito realizado nos Estados Unidos pelo Departamento de Justiça, entre os anos de 2010 e 2014, aponta que, a partir do ano de 1998, 17,7 milhões de mulheres americanas foram vítimas de estupro, contra 2,78 milhões de homens violentados sexualmente no mesmo período. As mulheres de 16 a 19 anos são quatro vezes mais propensas a serem estupradas, já mulheres universitárias, entre 18 e 24 anos, possuem o triplo dessa propensão. Na mesma faixa etária, as não universitárias possuem quatro vezes mais probabilidade de serem estupradas ${ }^{23}$.

\section{Conclusões}

$\mathrm{O}$ aspecto qualitativo da pesquisa possibilitou demonstrar a subjetividade das situações de violência pertinentes a essas mulheres, por meio de relatos expressos de próprio punho, que, na perspectiva da pesquisa qualitativa, possuem como característica a valorização do caráter histórico das relações de poder, das percepções e interpretações humanas ${ }^{\mathbf{2 4}}$.

Nesse sentido, a contribuição da pesquisa qualitativa esteve na riqueza de dar voz às mulheres nesse doloroso processo histórico.

Debater sobre a violência sexual e todo o contexto de relações de poder, patriarcais, que acompanham historicamente nossa sociedade 
se faz imprescindível cada vez mais. Refletir a submissão das mulheres, a cultura machista, é algo que deve se propagar nas relações sociais, no intuito de combater incessantemente quaisquer formas de violência. Não é possível a disseminação da chamada cultura da paz se as mulheres não puderem transitar por espaços públicos e privados, sob a ameaça de serem grotescamente violentadas.

As formas fortuitas de abordagem desses agressores, as ameaças perpetradas e a não procura dessas mulheres por qualquer espécie de ajuda após o ato demonstram o grande poder desses homens, impactando nas decisões e encaminhamentos de tais situações.

Os relatos descritos pelas participantes do estudo, o que sentiram, o que pensaram em fazer ou em não fazer após a violência, os temores que as assombraram, as lembranças remetem a refletir a impossibilidade de julgamentos de situações tão complexas.

Nesse sentido, aos profissionais, cabe o acolhimento, bem como o cuidado em não revitimizar as mulheres atendidas, por meio de condutas baseadas em suas percepções pessoais. $\mathrm{O}$ respeito por tais histórias e a prestação imediata da assistência, nesses casos, são fundamentais para minimizar as sequelas da violência.

Por meio dos relatos, fica expressa a necessidade de discutir muito mais sobre violência sexual, promovendo possibilidades de demonstrar os seus riscos iminentes à sociedade, desmistificando falsos conceitos que dificultam $o$ acesso das mulheres ao atendimento adequado. $\mathrm{O}$ desconhecimento do atendimento de saúde pode ser um dos motivos em buscar imediatamente os serviços de saúde, mas a carga moral e a carga julgadora que culpabiliza quem não tem culpa são também os grandes responsáveis pelo silêncio dessas mulheres. Culpas insensatas que agravam ainda mais todas as dimensões das sequelas da violência.

O objetivo de reconhecer os discursos expressos nos TRC realizados na solicitação do abortamento legal subsidiou ou até mesmo comprovou, por meio das histórias e dos olhares das mulheres violentadas, todo o poder masculino exercido no recorte investigado. Sendo a realidade objetiva considerada para além do fenômeno aparente, foi possível inferir relações de poder dos agressores para com suas vítimas, expressando o domínio, o pertencimento, bem como as agressões físicas, psicológicas, sexuais e morais expressas nos relatos investigados. Demonstra que a violência sexual não tem um perfil específico, pois a grande questão não está nas mulheres violentadas, no estereótipo destas. O perfil da violência está, na verdade, no agressor, nas relações entre homens e mulheres, na garantia de que mulheres podem ser violadas em diferentes espaços, em diferentes circunstâncias. Por essa razão, fazem-se imprescindíveis discussões e reflexões sobre o crime de violência sexual, buscando desconstruir conceitos solidificados, tais como os que cristalizam a culpa das mulheres vitimadas.

Para os profissionais de saúde, a pesquisa pode significar o estabelecimento de relações empáticas perante o drama de uma gestação em decorrência de violência sexual, apresentando a estes o processo, o que, muitas vezes, na prática, não é possível mediante atendimentos fragmentados. Ainda nesse quesito referente a relações de empatia, pode suscitar, por meio do conhecimento, o desejo de atuar em uma área ainda evitada por muitos profissionais.

Dar visibilidade às situações de violência sexual e suas consequências - uma delas, a gestação - é de suma importância. O direito de interromper a gravidez proveniente de crime de estupro garantido há 77 anos ainda é um tema absolutamente controverso. Qualquer intenção política de ameaçar tal direito demonstra a misoginia presente em tal questão; é afirmar que mulheres e meninas são culpadas por serem violentadas. Mais que isso, é confirmar o retrocesso de um processo que sequer evoluiu. Não somente as mulheres devem se indignar com tamanha atrocidade, mas toda a sociedade, todos aqueles que acreditam que criminalizar vítimas nunca pode ser o caminho para uma sociedade que almeja ser justa e pacífica. O caminho está invertido, 
os retrocessos buscam engessar o papel das mulheres, retirando-lhes a autonomia. Nessa perspectiva, a negação da perpetração da violência sexual contra as mulheres se configura em um grande desserviço.

A violência sexual epidêmica, assim como as demais violências de outras naturezas, demonstra que ainda há homens que não aceitam a independência das mulheres, não tolerando sua presença em espaços públicos. Os números dessa violência dão visibilidade ao que se considera ser uma representatividade da impossibilidade do direito de ir e vir das mulheres, tornando perigoso o cotidiano de todas.

Por fim, com esta pesquisa, intencionou-se contribuir para a visibilidade da violência, utilizando-se, para tanto, de um software de análise qualitativa, o que permitiu suscitar muitas outras possibilidades de pesquisas e de acesso àqueles que desconhecem o assunto, mas que se sensibilizam e desejam enfrentá-lo. Imaginar a violência vivenciada nunca será o suficiente, mas acolher sem discriminar é indispensável.

\section{Colaboradores}

Lima MCD (0000-0002-2044-0439)* contribuiu para a concepção, o planejamento, a análise e interpretação de dados, revisão crítica do conteúdo e aprovação da versão final do manuscrito. Larocca LM (0000-00018107-2572)* contribuiu para o planejamento, a análise e interpretação de dados, revisão crítica do conteúdo e aprovação da versão final do manuscrito. Nascimento DJ (00000003-0293-3042)* contribuiu para a revisão crítica do conteúdo e aprovação da versão final do manuscrito.

\section{Referências}

1. Abrahams N. Worldwide prevalence of non-partner sexual violence: a systematic review 2014. The Lancet [internet]. [acesso em 2015 out 3]. Disponível em: http://www.thelancet.com/journals/lancet/article/ PIIS0140-6736(13)62243-6/fulltext/.

2. Fórum Brasileiro de Segurança Pública. $9^{\circ}$ Anuário Brasileiro de Segurança Pública. São Paulo: FBSP; 2015.

3. Brasil. Lei $\mathrm{n}^{\circ} 12.015$ de 07 de agosto de 2009. Altera o Título VI da Parte Especial do Decreto-Lei no 2.848, de 7 de dezembro de 1940. Código Penal. Diário Oficial da União. 10 Ago 2009.
4. Brasil. Ministério da Saúde, Secretaria de Políticas de Saúde, Departamento de Gestão de Políticas Estratégicas, Área Técnica Saúde da Mulher. Norma Técnica de Prevenção e Tratamento dos Agravos Resultantes da Violência Sexual contra Mulheres e Adolescentes. Brasília, DF: Ministério da Saúde; 1999.

5. Curitiba. Secretaria Municipal da Saúde. Atenção à Mulher em Situação de Violência. Curitiba: Prefeitura; 2002.

6. Brasil. Decreto-Lei n ${ }^{\circ} 2848$, de 07 de dezembro de 1940. Código Penal. Diário Oficial da União. 31 Dez 1940.
*Orcid (Open Researcher and Contributor ID). 
7. Brasil. Ministério da Saúde, Secretaria de Atenção a Saúde, Departamento de Ações Programáticas Estratégicas. Atenção Humanizada ao Abortamento: norma técnica. 2. ed. Brasília, DF: Ministério da Saúde; 2010.

8. Kosik K. Dialética do Concreto. 2. ed. Rio de Janeiro: Paz e Terra; 1995.

9. Barwinski SLLB. O abortamento à luz do direito. In: Andrade RP, editor. Violência Sexual Contra Mulheres: aspectos médicos, psicológicos, sociais e legais do atendimento. Curitiba: Universidade Federal do Paraná; 2016.

10. Brasil. Ministério da Saúde, Secretaria de Políticas de Saúde, Departamento de Gestão de Políticas Estratégicas, Área Técnica Saúde da Mulher. Norma Técnica de Prevenção e Tratamento dos Agravos Resultantes da Violência Sexual contra Mulheres e Adolescentes. Brasília, DF: Ministério da Saúde; 2012.

11. Brasil. Ministério da Justiça e Cidadania, Secretaria Especial de Políticas para as Mulheres. Fluxo de Atendimento em Saúde para Mulheres e Adolescentes em Situação de Violência Sexual. Brasília, DF: Ministério da Justiça e Cidadania; 2011.

12. Gil AC. Estudo de Caso. São Paulo: Atlas; 2009.

13. Tobar F, Yalour MR. Como fazer teses em saúde pública: conselhos e idéias para formular projetos e redigir teses e informes de pesquisa. 20. ed. Rio de Janeiro: Fiocruz; 2001

14. Souza FN, Costa AP, Moreira A, et al. WEBQDA: Manual de Utilização Rápida [internet]. Aveiro: Universidade de Aveiro; 2016 [acesso em 2017 jun 6]. Disponível em: https://app.webqda.net/Fontes/Manual_de_Utilizacao_webQDA.pdf.

15. Paraná. Secretaria de Estado da Saúde. Regionais de saúde [internet]. [acesso em 2019 jun 6] Disponível em: http://www.saude.pr.gov.br/modules/conteudo/ conteudo.php? conteudo=2752.
16. Lima MCD. Abortamento legal: estudo de caso num hospital público do sul do país [dissertação] [internet]. Curitiba: Universidade Federal do Paraná; 2017. 118 p. [acesso em 2019 mar 22]. Disponível em: https://acervodigital.ufpr.br/handle/1884/52937.

17. Universidade de Aveiro. Software webQDA ${ }^{\circledast}$ [internet]. [acesso em 2017 maio 29]. Disponível em: https://app.webqda.net/?idioma=pt-PT.

18. Machado CL, Fernandes MAS, Osis MJD, et al. Gravidez após violência sexual: vivências de mulheres em busca da interrupção legal. Cad. Saúde Pública. 2015; 31(2):345-353.

19. Machado LZ. O patriarcado não está na cabeça das feministas. Radis. 2016; 166:21-22.

20. Prata ARS. A vítima de estupro já chega na delegacia com culpa [entrevista] [internet]. Carta Capital. 31 maio 2016 [acesso em 2019 jun 3]; Disponível em: https://www.cartacapital.com.br/sociedade/ping-ana-rita.

21. Instituto de Pesquisa Econômica Aplicada. Sistema de Indicadores de Percepção Social (Sips). Tolerância social à violência contra as mulheres. Brasília, DF: Instituto de Pesquisa Econômica Aplicada; 2014.

22. Cerqueira D. Ipea admite que faltam dados sobre violência sexual [internet]. [acesso em 2017 maio 29]. Disponível em: http://agenciabrasil.ebc.com.br/ge$\mathrm{ral} /$ noticia/2014-04/ipea-admite-que-faltam-dados-sobre-violencia-sexual.

23. Rape, abuse \&incest national network (rainn) [internet].Victims of Sexual Violence: Statistics; 2019 [acesso em 2019 jun 3]. Disponível em: https://www.rainn. org/.

24. Minayo MC. O desafio do conhecimento: pesquisa qualitativa em saúde. 12. ed. São Paulo: Hucitec; 2010.

Recebido em 28/08/2018

Aprovado em 17/03/2019

Conflito de interesses: inexistente

Suporte financeiro: não houve 